\title{
O Imaginário Coletivo de Médicos sobre o uso de Cannabis sativa
}

\section{The Collective Imaginary of Doctors on the use of Cannabis sativa}

DOI: $10.46814 /$ lajdv2n6-012

Recebimento dos originais: 01/09/2020

Aceitação para publicação: 30/10/2020

Isabela Raimundo Paranhos Giesta

Especialista em Endocrinologia Pediátrica pelo Instituto de Puericultura e Pediatria Martagão Gesteira (IPPMG/UFRJ)

Instituição: Instituto de Puericultura e Pediatria Martagão Gesteira (IPPMG/UFRJ)

Endereço: Rua Bruno Lobo, 50 - Cidade Universitária, Rio de Janeiro - RJ, Brasil E-

mail: draisabelaparanhos@gmail.com

\section{Maria Auxiliadora Motta Barreto}

Doutora em Psicologia como Profissão e Ciência pela PUC Campinas, Mestre em Educação pelo Centro Universitário Salesiano Instituição: Universidade de São Paulo - EEL/USP

Endereço: Estrada municipal do Campinho, S/N, Campinho, Lorena/SP - CEP: 12.602-810

E-mail: maribarreto@usp.br

\section{RESUMO}

O uso de Cannabis sativa (maconha) é popularmente conhecido, sendo a droga ilícita mais comumente utilizada, e considerada por seus usuários como um entorpecente não prejudicial. $\mathrm{O}$ presente artigo tem por objetivo considerar o imaginário coletivo de médicos sobre o uso da maconha, pois, frequentemente, são estes os primeiros profissionais procurados quando a utilização dessas substâncias denuncia problemas de saúde. São estes, ainda, que posteriormente proporcionam um tratamento e/ou encaminhamento adequados aos usuários. Foram realizados encontros individuais com médicos voluntários, de variadas idades, especialidades médicas e ambos os sexos, utilizando o procedimento de Desenho-Estória com Tema, tendo por base a abordagem psicanalítica, ensejando captar campos psicológico-vivenciais não conscientes.

Palavra-chave: Cannabis sativa, Saúde Pública, Médicos, Cuidados Médicos, Psicanálise.

\begin{abstract}
The use of Cannabis sativa (marijuana) is popularly known, being the most commonly used illicit drug, and considered by its users as a non-harmful narcotic. This article aims to reflect on the collective imagination of doctors about the use of marijuana, since, many times, these are the first professionals sought when the use of these substances denounces health problems. They are also those who subsequently provide users with the appropriate treatment and / or referral. Individual meetings were held with volunteer doctors, of various ages, medical specialties and of both sexes, using the Drawing-Story with Theme procedure, based on the psychoanalytical approach, allowing the capture of unconscious psychological-experiential fields.
\end{abstract}

Keyword: Cannabis sativa, Public health, Doctors, Medical care, Psychoanalysis. 


\section{INTRODUÇÃO}

Este artigo é resultado de um Projeto de Iniciação Científica desenvolvido com o apoio do CNPq - PIBIC por uma aluna de um curso de medicina de uma escola no interior do Estado do Rio de Janeiro.

O trabalho é uma atividade do homem e também uma mercadoria comercial criada pela sociedade. A profissão de médico pode ser considerada como fenômeno de grande complexidade, que envolve, em parte, o viver emocional do ser humano (BARRETO E AIELLO-VAISBERG, 2007; BARRETO, ET. AL., 2009).

É importante lembrar que, esse viver emocional resulta no imaginário do ser humano, que se forma de componentes tanto conscientes como inconscientes, além de individuais e coletivos, a partir da vivência do indivíduo, influenciando, sobremaneira, no seu modo profissional e na forma como a atuação médica será recebida e processada pelo paciente (BARRETO, 2006).

Consideramos que o abuso de drogas e sua influência no comportamento físico e emocional do usuário constituem um problema de saúde pública. O reconhecimento e o imaginário dessa situação-problema decorrente da rotina do uso de tóxicos não são manifestações isoladas e simples de serem reproduzidas.

Bleger (1963) afirma que o homem é um ser essencialmente social e, sendo assim, cada homem expressa seu ser individual e coletivamente. Por esses motivos, optamos por realizar este trabalho pela via da captação de campos psicológicos não conscientes relativos ao imaginário de médicos acerca do uso de maconha (HERMANN, 1979).

O imaginário coletivo é, então, a manifestação simbólica de subjetividade de coletividades (BARRETO e AIELLO-VAISBERG, 2010; MARTINS, 2007). Assim, consideramos imaginário coletivo como a concepção de um coletivo sobre determinado tema e optamos por utilizar o conceito de "imaginário coletivo" desenvolvido por Aiello-Vaisberg (1999).

O objetivo desse trabalho é considerar o imaginário coletivo de profissionais médicos sobre o uso de maconha. Foram analisados graduados de ambos os sexos e variadas especialidades médicas e idades.

\section{METODOLOGIA}

A atividade imaginativa é concebida como conduta, em termos de experiência subjetiva como acontecimento dotado de múltiplos sentidos emocionais (MARTINS, 2007). O imaginário coletivo de diversos grupos sociais requer uma metodologia de pesquisa que viabilize justamente a abordagem do coletivo. 
$\mathrm{Na}$ realização deste projeto de iniciação científica, foi utilizada uma abordagem que permitisse a participação voluntária de médicos, com o objetivo de elucidar o imaginário coletivo desses profissionais no que diz respeito ao uso de Cannabis sativa.

A pesquisa foi realizada nos anos de 2012 e 2013 com 12 professores médicos de uma escola de medicina no interior do Estado do Rio de Janeiro e um professor médico também voluntário, porém, de outra escola. As reuniões realizadas com cada voluntário aconteceram individualmente, na presença da aluna pesquisadora previamente capacitada e supervisionada pela orientadora do projeto quanto ao método proposto.

Elegemos como opção metodológica o procedimento de Desenho-Estória com Tema, com o objetivo de captar campos psicológico-vivenciais inconscientes. E tomando por base a ideia de Bleger (1963) de que o homem é um ser fundamentalmente social, abordamos os médicos enquanto representantes de uma coletividade (BARRETO, 2009).

O projeto foi submetido e devidamente autorizado por um Comitê de Ética em Pesquisa em Seres Humanos (CoEPS), CAAE 07086812.20000.5237, antes do início da coleta de dados.

Cada participante recebeu uma folha de papel sulfite A4, um lápis grafite e uma borracha, e foi solicitado o seguinte: “desenhe uma pessoa que use maconha e, depois, escreva uma estória sobre essa pessoa no verso da folha”. Pedimos que o participante não assinasse a folha, mas anotasse idade, sexo e especialidade médica.

A abordagem escolhida constitui um meio que facilita o acesso ao imaginário coletivo e que nos aproxima da verdadeira concepção de um grupo sobre os usuários de maconha (BARRETO, 2006).

Além da realização dos desenhos-estória, solicitamos que os participantes preenchessem o Termo de Consentimento Livre e Esclarecido (TCLE) comunicando a data da realização da pesquisa, o nome completo do participante e RG ou CRM. Este termo forneceu breve informação sobre a execução da pesquisa, isentando os profissionais voluntários de quaisquer privilégios, garantindo sigilo e privacidade quanto à identificação do participante, e consentindo a sua participação no trabalho.

O método de coleta de dados de Desenho-Estória com Tema utilizado foi baseado nos moldes desenvolvidos em 2004 por Aiello-Vaisberg e na concepção de Trinca (1987) para a investigação de imaginários coletivos. Esse artifício é utilizado, principalmente, em temas de difícil acesso, com o objetivo de conseguir captar e elucidar percepções que estão além do campo consciente do entrevistado (AIELLO-VAISBERG, 2003; BARRETO, 2006). 
Assim, a pesquisa foi conduzida como um processo de investigação psicanalítica, e o método do desenho foi escolhido, pois, desenhando, o participante é mais espontâneo, permitindo o acesso às ideias primárias, às emoções e à expressão de sentimentos de modo mais espontâneo, visto que o desenho produz um ambiente favorável para a interação e a descontração (PEREIRA, 2003; FARIAS, 2005).

Para investigar os aspectos mais profundos da vida de cada sujeito pesquisado, optamos pelo desenho, por criar esse ambiente de pesquisa mais livre de controle racional. Sendo um processo inconsciente, o desenho retrata, em linguagem gráfica e livre o sentimento de quem o desenhou (FARIAS, 2005).

Em coerência com o método, foi realizada uma análise compatível para compreender a expressão dos participantes, ressaltando o conceito de que não haveria respostas certas ou erradas, uma vez que a pesquisa busca o que apareceria do conjunto, revelando campos psicológicos não conscientes (BARRETO, 2006).

Cada desenho foi analisado individualmente, tendo sido numerado e atribuído um título, o qual deveria remeter à ideia principal percebida no desenho. Os dados observados foram compilados em uma tabela para que fossem destacados os campos psicológicos prevalentes.

\section{RESULTADOS}

A partir da atividade realizada com os participantes da pesquisa, foram obtidos 13 desenhosestória. Todos os desenhos foram incluídos na análise por estarem seguindo as solicitações desejadas; mantiveram o padrão de execução e apresentaram desenho e estória.

Através da análise dos desenhos, observou-se que a minoria deles não atribui prejuízo ao uso da maconha, assim como, pequena também é a parcela de voluntários que apresentam em seus desenhos usuários do sexo feminino.

Foi verificada a predominância de alguns campos psicológicos não conscientes, destacamos, o uso da maconha como válvula de escape, prejuízos futuros, grupos de uso e alterações pessoais e de comportamento, que serão descritos a seguir.

\subsection{VÁLVULA DE ESCAPE}

Neste campo psicológico os autores representam um usuário em busca de refúgio e prazer, almejando viver aqueles momentos do efeito da droga em um mundo que não é o seu. Associam o vício à fuga da realidade e do presente. No desenho ilustrado abaixo "Devaneio", o autor enumera a 
esperança de dias melhoras melhores, o alívio e o relaxamento como efeitos provocados pela maconha.

Figura 1 - "Devaneio"

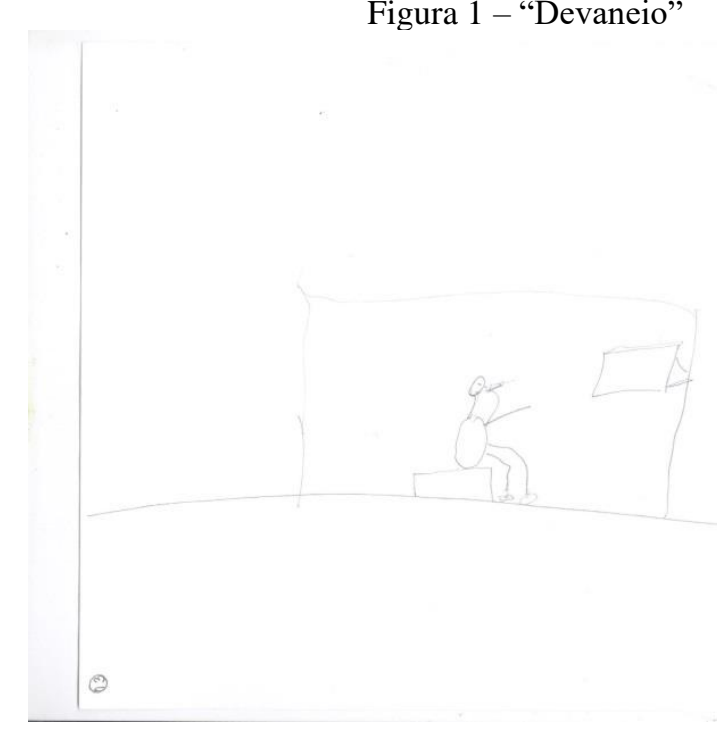

\subsection{PREJUÍZOS FUTUROS}

Neste campo psicológico o sujeito do desenho não apresenta prejuízos momentâneos ou a curto prazo provocados pela droga. Os prejuízos são principalmente intelectuais e emocionais, como na estória referente à figura dois. O jovem ilustrado apresentava projetos para o futuro, e com o uso da droga ao longo dos anos suas perspectivas e sonhos se esvaíram.

Figura 2 - "O sonho que virou fumaça"

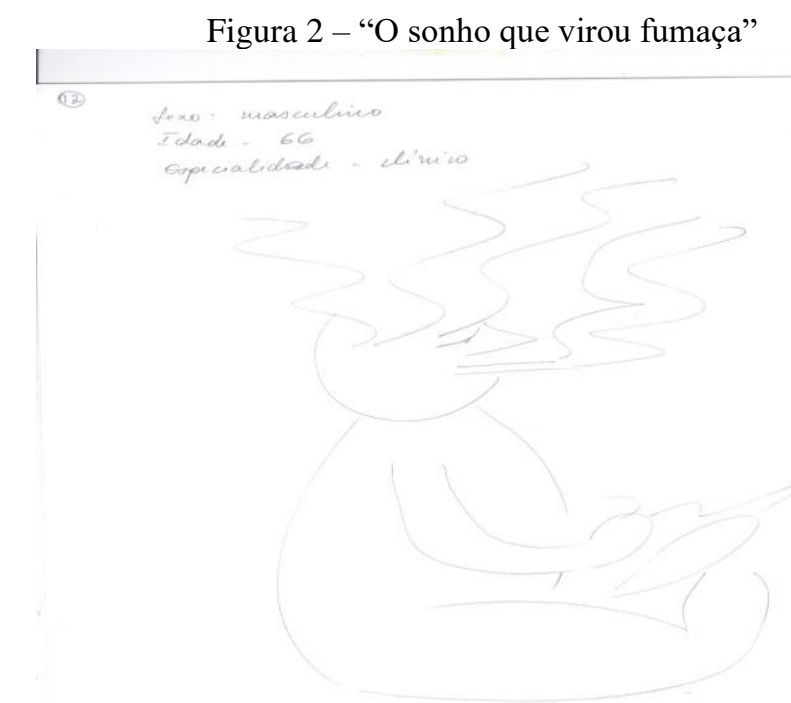




\subsection{GRUPOS DE VÍCIOS}

De maneira predominante a maconha aparece associada a um "círculo vicioso". O usuário, em sua maioria, é jovem e está vivendo conflitos familiares e/ou pessoais. Estas desordens os levam a buscar consolo em vícios, como é o caso do desenho intitulado "gangorra".

O usuário representado na figura possui 46 anos, é médico e fuma maconha diariamente desde os 13 anos. Já fez uso de cocaína após intenso consumo de maconha e relaciona o seu uso à influência de amigos e outras drogas, representando um grupo que associa o uso da droga ao meio social que o usuário está inserido.

Figura 3 - "Trampolim"

\subsection{ALTERAÇÕES PESSOAIS E DE COMPORTAMENTO}

A maconha aparece em diversas histórias como responsável pelo afastamento do usuário de seu meio social e mudanças no seu comportamento. Observaram-se mudanças na aparência e nas atitudes do indivíduo. No desenho da figura quatro os efeitos da droga, de acordo com o descrito na estória, resultaram em uma mulher de aparência envelhecida, emagrecida e com hábitos precários de higiene, retratando a incoerência com a jovem de boas condições financeiras, bonita e interessante rotulada no início do texto. 
Figura 4 - "Pacote completo"

\section{CONSIDERAÇÕES FINAIS}

$\mathrm{Na}$ análise dos desenhos-estórias com tema percebemos que os profissionais médicos que participaram da pesquisa, assim como a maioria da população médica que representam, retratam conceitos pré-concebidos e sem manifestações reflexivas e concretas acerca do que realmente pensam sobre o uso da droga. Dessa maneira, apenas reproduzem o que provavelmente ouviram falar nos meios sociais que participou durante a sua vida

Quanto ao uso da Cannabis sativa, observamos um discurso aprendido e repetido acerca dos malefícios provocados pelo uso da droga. Este fato nos leva a considerar que os médicos se apropriam de informações pré-concebidas, abrindo mão de suas próprias convicções a respeito do tema.

A partir dos resultados observados nessa pesquisa, enfatizamos a importância de incentivar os profissionais médicos a refletir sobre suas próprias concepções acerca do uso da droga, para que dessa forma possam atuar profilaticamente junto à população que atendem no exercício da medicina. 


\section{REFERÊNCIAS}

AIELlO-VAISBERG, T. M. J. Encontro com a loucura: Transicionalidade e ensino de psicopatologia. $342 \mathrm{f}$. Tese de livre docência não publicada - Departamento de psicologia clínica, Universidade de São Paulo, 1999.

AIELLO-VAISBERG, T. M. J. Ser e fazer: interpretação e intervenção na clínica winnicottiana. Psicologia USP, São Paulo, IPUSP, v. 14, n. 1, 2003.

AIEllo- VAISBERG, T. M. J.; AMBROSIO, F. F. (Orgs.) Cadernos Ser e Fazer: o brincar. São Paulo: IPUSP, 2004.

BARRETO, M. A. M. Do vôo preciso: considerando o imaginário coletivo de adolescentes. 197 f. Tese (Doutorado) - Centro de Ciências da Vida, Programa de Pós-Graduação em Psicologia, Pontifícia Universidade Católica de Campinas, 2006.

BARRETO, M. A. M. et. al. Ser médico: o imaginário coletivo de estudantes de medicina acerca da profissão de médico. Cadernos UniFOA, Rio de Janeiro, FOA, n. 11, dez., 2009.

BARRETO, M. A. M.; AIELLO-VAISBERG, T. M. J. Escolha profissional e dramática do viver adolescente. Psicologia e Sociedade, ABRAPSO, vol. 19, n. 1, jan./abr., 2007.

BARRETO, M. A. M.; AIELLO-VAISBERG, T. M. J. O tornar-se adulto no imaginário coletivo de adolescentes interioranos. Psicologia em Revista, Belo Horizonte, PUC Minas, v. 16, n. 2, ago., 2010 .

BARRETO, M. A. M.; REIS, C. N.; MIRANDA, I. B. de; JARDIM, L. C. R.; TEIXEIRA, M. T. Ser médico: o imaginário coletivo de estudantes de medicina acerca da profissão de médico. Revista Cadernos UniFOA, Rio de Janeiro, FOA, n. 11, dez., 2009.

BLEGER, J. Psicologia de la conducta. Buenos Aires: Paidós, 1963.

FARIAS, F. L. R. de; FUREGATO, A. R. F. O dito e o não dito pelos usuários de drogas, obtidos mediante as vivências e da técnica projetiva. Revista Latino-Americana de Enfermagem, Ribeirão Preto, EERP/USP, vol. 13, n. 5, set./out., 2005.

HERRMANN, F. A. Andaimes do real: o método da psicanálise. São Paulo: EPU, 1979.

MARTINS, P. C. R. O amante competente e outros campos do imaginário coletivo de universitários sobre dificuldades sexuais masculinas. $176 \mathrm{f}$. Tese (Doutorado) - Centro de Ciências da Vida, Programa de Pós-Graduação em Psicologia, Pontifícia Universidade Católica de Campinas, 2007.

PEREIRA, M. A. O; JÚNIOR, A. P. Transtorno mental: dificuldades enfrentadas pela família. Escola de Enfermagem da USP, São Paulo, USP, vol. 37, n.4, 2003.

TRINCA, W. Investigação clínica da personalidade: O desenho livre como estímulo da percepção temática. São Paulo: EPU, 1987. 